BMC

Evolutionary Biology

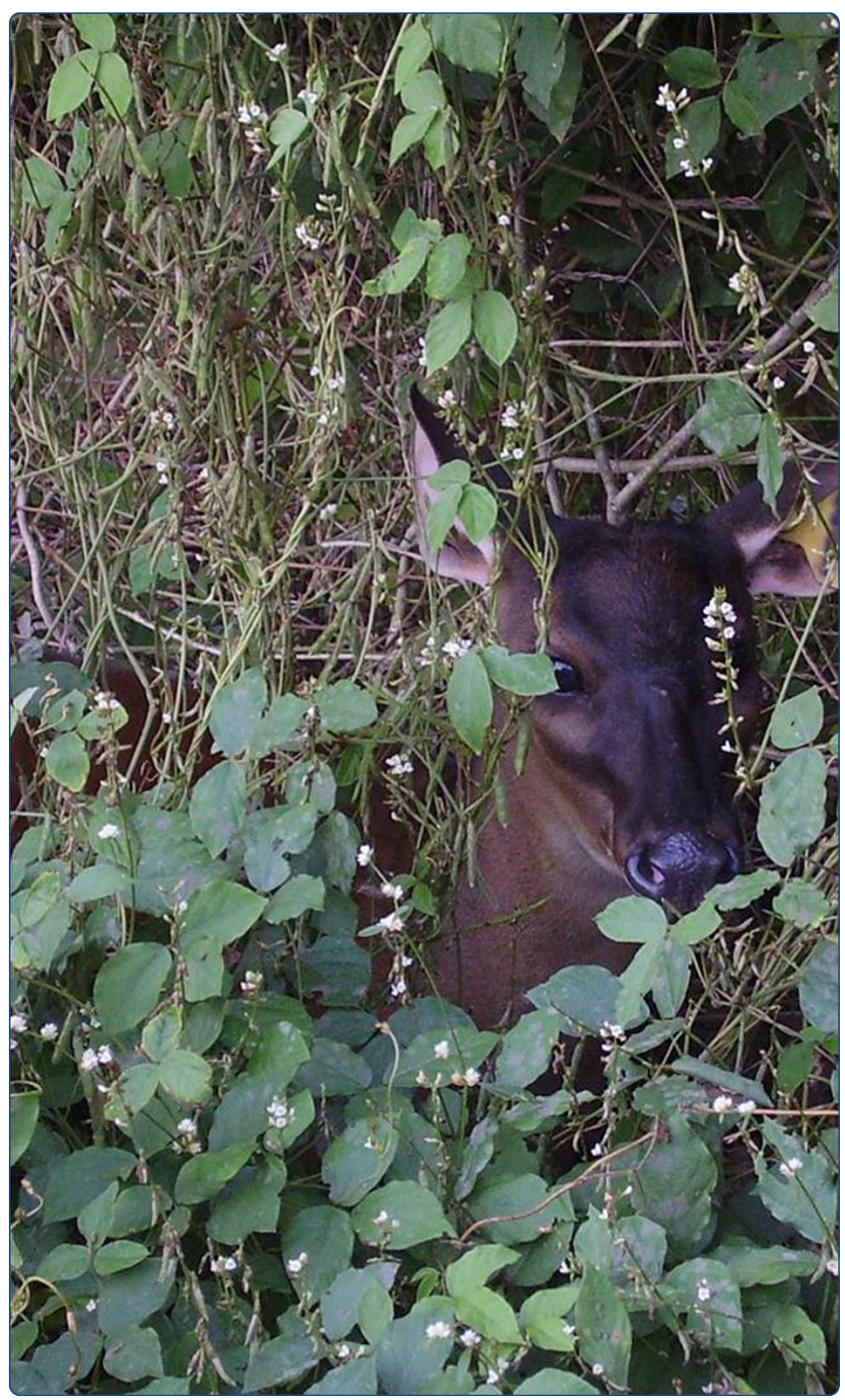

\title{
The role of chromosome variation in the speciation of the red brocket deer complex: the study of reproductive isolation in females
}

Cursino et al. 


\title{
The role of chromosome variation in the speciation of the red brocket deer complex: the study of reproductive isolation in females
}

\author{
Marina Suzuki Cursino ${ }^{1,2^{*}}$, Maurício Barbosa Salviano ${ }^{3}$, Vanessa Veltrini Abril ${ }^{1}$, Eveline dos Santos Zanetti ${ }^{1}$ \\ and José Maurício Barbanti Duarte $e^{1,2}$
}

\begin{abstract}
Background: The red brocket deer, Mazama americana, has at least six distinct karyotypes in different regions of South America that suggest the existence of various species that are today all referred to as M. americana. From an evolutionary perspective, the red brockets are a relatively recent clade that has gone through intense diversification. This study sought to prove the existence of post-zygotic reproductive isolation in deer offspring between distinct chromosome lineages. To achieve this, inter-cytotype and intra-cytotype crosses were performed, which resulted in both F1 hybrid $(n=5)$ and pure offspring $(n=3)$ in captivity.

Results: F1 females were analyzed in terms of their karyotypes, ovarian histology, estrous cycles and in vitro embryo production. Pure females presented parameters that were similar to those previously reported for M. Americana; however, the parameters for hybrid females were different. Two hybrids were determined to be sterile, while the remaining hybrids presented characteristics of subfertility.

Conclusions: The results support the existence of well-established reproductive isolation among the most distant karyotype lineages and elucidates the need to define all karyotype variants and their geographical ranges in order to define the number of species of red brocket.
\end{abstract}

Keywords: Cryptic species, Hybrids, Chromosomal polymorphism, Mazama americana

\section{Background}

Among mammals, the Cervidae family is known for its wide chromosomal diversification and this is also true for the genus Mazama. This genus is considered one of the most complex [1], together with the genus Muntiacus [2]. The ancestral forms of the red Mazama came into South America approximately 2.5 million years ago, and from that time branched out into various species (M. bororo, $M$. nana, $M$ rufina, $M$. americana) $[1,3,4]$. Following cytogenetic studies, the ancestral karyotype of the Cervidae was defined as $2 \mathrm{n}=70$ and $\mathrm{FN}=70[5,6]$.

\footnotetext{
* Correspondence: marina.suzuki@gmail.com

'NUPECCE - Núcleo de Pesquisa e Conservação de Cervídeos, Departamento de Zootecnia, FCAV -Faculdade de Ciências Agrárias e Veterinárias, UNESPUniversidade Estadual Paulista, CEP 14884-900, Jaboticabal, SP, Brazil ${ }^{2}$ Programa de Pós-graduação em Medicina Veterinária, Reprodução Animal, FCAV, UNESP, CEP 14884-900 Jaboticabal, SP, Brazil

Full list of author information is available at the end of the article
}

The red brocket group accumulated multiple centric and tandem fusions leading to distinct karyotypes [2], such as $2 \mathrm{n}=36$ to $41+1-6 \mathrm{~B}$ and $\mathrm{FN}=58$ in $M$. nana [7] and independently, $2 \mathrm{n}=34+4-5 \mathrm{~B}$ and $\mathrm{FN}=46$ in $M$. bororo [3]. Moreover, the genus presents high intraspecific and interspecific chromosomal polymorphism [4,5,8-10].

In the case of $M$. americana, current studies discuss the possibility of a cryptic species complex due to the significant intraspecific chromosomal variation $[3,4]$. Significant differences in the patterns of karyotypic evolution in $M$. americana provide strong evidence that the Central and South American lineages are really different species. M. temama from Mexico, previously classified as $M$. americana temama, presented a karyotype with $2 \mathrm{n}=$ 50, $\mathrm{XX} / \mathrm{XY}$ and $\mathrm{FN}=72[8]$.

In Brazil, M. americana has a wide geographical distribution ranging from the North to the South of the country [10], and specimens from different geographical

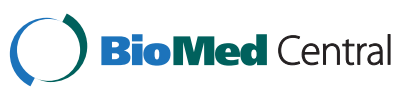


locations present high levels of genetic differentiation and diversification in haplotypes and karyotypes [4]; however, they are morphologically reported as a single species with no taxonomic subdivisions [11].

The karyotypes of $M$. americana (species complex) seem to be derived from a single common ancestral karyotype with $2 \mathrm{n}=52 / 53+3-4 \mathrm{~B}, \mathrm{XX} / \mathrm{XY} 1 \mathrm{Y} 2$ and $\mathrm{FN}=$ 54 , which arose after successive tandem fusions and an $\mathrm{X}$-autosome fusion [5,9]. In Brazil, the species has been divided into six distinct cytotypes: Rondônia (Ro: $2 \mathrm{n}=$ 42 ㅇ- $43 \hat{\jmath} / \mathrm{NF}=49)$, Juína (Ju $2 \mathrm{n}=43-44+9 / 44-45 \hat{\jmath}+3-$ $6 \mathrm{~B}$ and $\mathrm{FN}=48$ ), Jarí (Ja: $2 \mathrm{n}=49 \hat{\jmath} / \mathrm{NF}=56$ ), Carajás

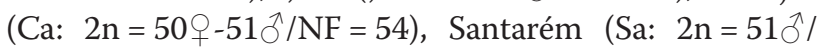
$\mathrm{NF}=56)$ and Paraná $\left(\operatorname{Pr}: 2 \mathrm{n}=52\right.$ ㅇ $\left.-53{ }^{\lambda} / \mathrm{NF}=56\right)$ [12].

Another recently discussed point regarding the taxonomy of the species was the discovery of two chromosome lineages: Lineage A, which includes the Rondônia and Juína karyotypes; and Lineage $B$, which includes the Jarí, Carajás, Santarém, and Paraná karyotypes [12]. Both lineages evolved from a common ancestor through different chromosomal rearrangements and present a high level of genetic differentiation and distance, which led Abril et al. to suggest the existence of two or more distinct species [12]. The chromosomal differentiation of each cytotype from the common ancestor $(2 n=52-53$; $\mathrm{FN}=54$ ) was achieved by the fixation of different rearrangements (Figure 1): i) Paraná, pericentric inversion; ii) Carajás, a rearrangement of the Paraná cytotype with another tandem-fusion translocation; iii) Santarém, a rearrangement of the Paraná cytotype with another centric-fusion translocation; iv) Jarí, a rearrangement of the Santarém cytotype with another centric-fusion translocation; v) Juína, a centric-fusion translocation and three tandem-fusion translocations; and vi) Rondônia, a rearrangement of the Juína cytotype with another tandemfusion translocation [12].

Most of the advances in chromosomal rearrangement, speciation and their relationship, have been theoretical, especially in mammals [13]. In general, models of chromosome speciation have the same point of view: the reduction

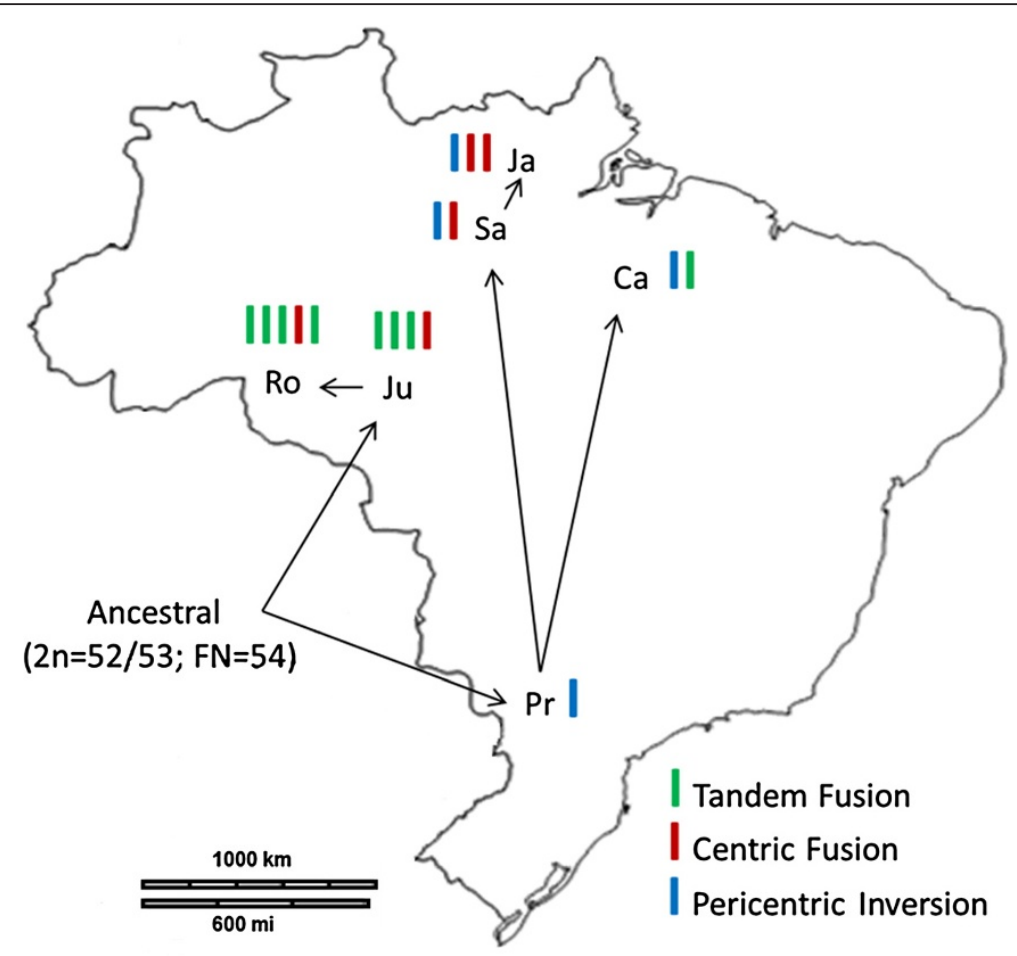

Figure 1 Chromosomal evolution network. Relationships of the 6 cytotypes of M. americana analyzed and their geographical distribution, modified from Abril et al. [12]. The ancestral karyotype originated the Linage A) (northwest of Brazil) and Linage B) (south and north of Brazil). The chromosomal differentiation of each cytotype from the common ancestor $(2 \mathrm{n}=52-53 ; \mathrm{FN}=54)$ was achieved by the fixation of different rearrangements: Linage $A$ is constitute by Ju: Juína $(2 n=44 / 45 ; F N=48)$ a centric-fusion translocation (red bar) and three tandem-fusion translocations (green bar), and Ro: Rondônia $(2 \mathrm{n}=42 / 43 ; \mathrm{FN}=46)$ a rearrangement of the Juína cytotype with another tandem-fusion translocation (green bar). The Linage B is constitute by Pr: Paraná $(2 n=52 / 53 ; F N=56)$ a pericentric inversion (blue bar) from the ancestral karyotype; Ca: Carajás ( $2 \mathrm{n}=50 / 51 ; \mathrm{FN}=54)$ a rearrangement of the Paraná cytotype with another tandem-fusion translocation (green bar); Sa: Santarém $(2 \mathrm{n}=50 / 51 ; \mathrm{FN}=56)$ a rearrangement of the Paraná cytotype with another centric-fusion translocation (red bar); and Ja: Jarí $(2 n=48 / 49 ; F N=56)$ a rearrangement of the Santarém cytotype with another centric-fusion translocation (red bar). $2 n=$ diploid number / $\mathrm{FN}=$ fundamental number. The colors bars indicate the chromosome rearrangements accumulated by the cytotype. 
of gene flow through the accumulation of chromosomal differences between the progenitor and their descendants that leads to impaired fertility or viability of interspecific hybrids [14]. Animals that are heterozygous for chromosome rearrangements may present anomalous pairings during meiosis, which results in failure during gametogenesis and unbalanced gamete production, both of which cause diminished fertility or even sterility in the organism [15].

One of the most common types of structural rearrangement between species or chromosomal races is the centric fusion or Robertsonian fusion [16]. Individuals heterozygous for a single centric fusion may present diminished reproductive capacity, even though the trivalent structures formed segregate normally during meiosis [17]. On the other hand, a hybrid individual, descendant of progenitors that have accumulated different Robertsonian fusions, can present infertility. This occurs in the Mus musculus complex, due to the accumulation of centric fusions between karyotypic races, hybrids present pentavalent structures during meiosis, which leads to the formation of unbalanced gametes and the reproductive isolation of the neospecies [18].

Tandem fusions follow the same pattern as centric fusions, i.e. they cause diminished fertility or a reduction in the fitness of the hybrid, which can lead to reproductive isolation due to the accumulation of rearrangements [19]. Tandem fusions appear to have a special role in the evolution of certain taxa, such as bovids [20]. The difference between swamp buffalo and river buffalo is a single tandem fusion, involving chromosomes 4 and 9 of the river buffalo karyotype [21]. A bull was described as exhibiting a $10 \%$ reduction in fertility due to a single tandem fusion [22]. In muntjac deer, 17 tandem fusions and three centric fusions differentiate the Chinese muntjac $(2 n=46)$ from the Indian muntjac $\left(2 \mathrm{n}=69 / 7{ }^{\lambda}\right)$ [23].

Another chromosome rearrangement that can be involved in speciation is chromosome inversion. Some models suggest that the presence of inversions can lead to genetic differentiation among species, or even to reproductive isolation in populations with gene flow, by reducing recombination between inverted and non-inverted genomic regions [24-26]. In contrast, species that present a high rate of inversion polymorphism, a synaptic adjustment can occurs during meiosis leading to heterosynapsis and chiasma suppression within heterozygous inverted regions and the hybrids are fertile and viable [25,27].

Traditionally, studies involving reproductive isolation seek to prove the presence of sterility or subfertility in hybrids. In order to evaluate the fitness of the female, reproductive parameters such as meiotic parameters in germ cells of fetuses have been used [28-30], together with histological evaluation of the ovaries [30-33] and successful reproduction involving the production of viable fawns $[34,35]$. Current techniques that produce viable results in a short period of time, such as in vitro testing, may also help to infer the reproductive capacity of female hybrids.

The presence of germ cells can be inferred through ovarian activity, which itself is strongly related to the regulation of steroid hormones, such as progesterone and estrogen [36]. A method that is commonly used to evaluate the ovaries of wild animals is the measurement of fecal progesterone metabolite levels (FPM) [37-39]. In the case of Neotropical deer, particularly M. gouazoubira, the characteristics of reproductive events have been studied using this method of monitoring the endocrine system [40-43].

The genetic balance of these germ cells can be inferred using an in vitro embryo production technique. Only oocytes that have a balanced genetic background are fertilizable and then capable of beginning embryogenesis [44-46].

Based on these discussions surrounding the taxonomy of the red brocket and in light of new reproductive technologies, this study sought to determine the presence or absence of post-zygotic reproductive isolation among the chromosomal lineages of the Mazama americana by evaluating the fertility of pure and hybrid females.

\section{Results}

\section{Hormone measurements}

The hormonal profile and the base concentration of FPM were used to determine the onset of puberty (ovarian activity), which varied from eight to 15 months of age (Figures 2 and 3). The females P2, H1, H3, and H4 experienced their first ovulations between eight and 10 months of age, while the females P1, P3, and H5 experienced the onset of puberty later, between 14 and 15 months of age. Two females did not show a cyclic profile similar to the others: the pure female P1, in which the onset of puberty was observed; and the hybrid female $\mathrm{H} 2$, which did not show any ovarian activity until 18 months-old.

\section{Histology of the ovaries}

Both the pure and hybrid females presented follicles in various stages of development, along with corpora lutea and corpora albicans; however, the hybrid females presented a smaller number of follicles than the pure females. Crossings between males from Lineage B ( $\mathrm{Pr}$ and $\mathrm{Ca}$; higher $2 \mathrm{n}$ ) and females from Lineage $\mathrm{A}$ (Ro and Ju; lower $2 \mathrm{n}$ ) produced sterile females ( $\mathrm{H} 1$ and $\mathrm{H} 2)$ that lacked follicular structures. However, crossings between males from Lineage A with females from Lineage B produced subfertile females ( $\mathrm{H} 3$ and $\mathrm{H} 4)$ that possessed follicular structures, though fewer than pure females. Despite being the result of a crossing between two cytotypes from the same lineage (Ju $\mathrm{x}$ Ro), specimen $\mathrm{H} 5$ 


\section{P1}

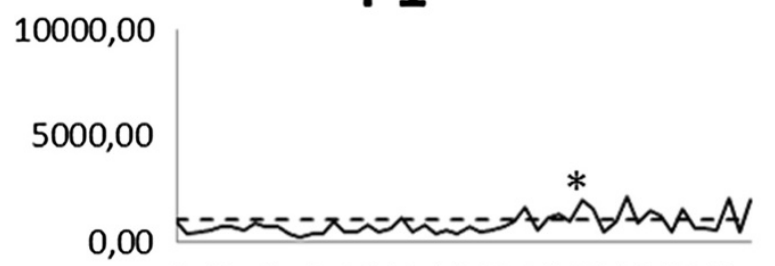

6789101112131415161718

Age (month)

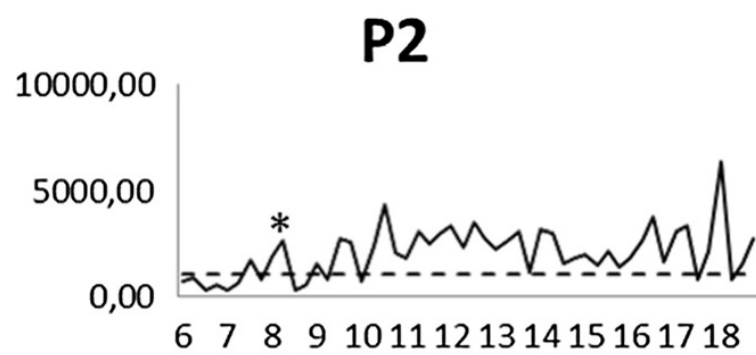

Age (month)

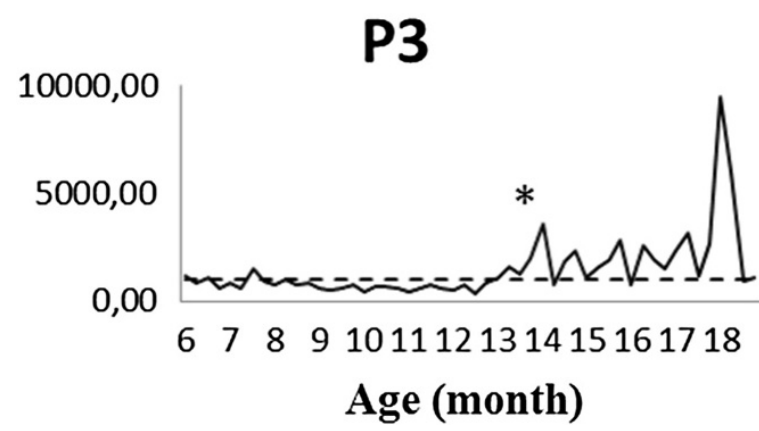

Figure 2 Hormonal profile of pure females. Concentrations are expressed in grams of feces/ng of fecal progesterone metabolites (FPM). The dotted line refers to the calculated mean baseline of progestogens. *First ovulation cycle observed.

presented fewer follicular structures and was more similar to the females $\mathrm{H} 1$ and $\mathrm{H} 2$ (Figure 4).

\section{Superovulation, follicular aspiration and in vitro production of embryos}

Pure females responded to superovulation treatment and provided a total of 26 aspirated oocytes $(8.67 \pm 3.06$ per female). The total amount of oocytes obtained from pure females using the slicing method (involving half an ovary from each female) was 105 (35 \pm 9 per female).

All of the oocytes were forwarded for maturation, fertilization, culture medium and development in vitro. Hoechst staining verified that $32.82 \%$ (43 out of 131) of the embryos experienced cleavage, $36.64 \%$ (48 out of 131) were considered unfertilized oocytes and $30.53 \%$ (40 out of 131) presented inconclusive structures. Development was halted in all of the embryos before the blastocyst stage, but we were still able to obtain five morulae with more than 16 cells (Figure 5).

The female hybrids $\mathrm{H} 1$ and $\mathrm{H} 2$ did not respond to superovulation treatment and showed no follicular development (Figure 6), while females H3, H4 and H5 developed follicles. Fourteen oocytes were obtained by aspiration (2.8 \pm 5.6 per female), and 36 oocytes $(7.2 \pm 11.57$ per female) were obtained using the slicing method on half of each ovary. Of these oocytes, 37 were forwarded for maturation, and 36 remained for fertilization, culture medium and development in vitro.

Hoechst staining revealed an $11.11 \%$ rate of fertilization (results that include cases of polyspermy) and a very low rate of cleavage (5.55\%). Sixteen of the 37 oocytes (44.44\%) were considered unfertilized, and 16 (44.44\%) produced inconclusive results. Development was halted in all of the embryos before the morula stage; division of only four to six cells was observed, even in the pronucleus stage.

\section{Discussion \\ Reproductive abilities}

The reproductive parameters analyzed in this study (FPM measurement, ovarian histology, response to superovulation and the production of embryos in vitro) provide conclusions concerning the reproductive abilities of pure females. The research methods used herein determined luteal phase profiles, the presence of ovarian structures, a satisfactory response to superovulation and embryos produced in vitro.

The hormone profile of FPM from the pure females indicated the presence of luteal phases, which represent ovarian activity [40,47-50], as well as the absence of reproductive seasonality in these animals [51,52]. Most female Cervidae experience their first ovulation at approximately one year of age, while females from smaller species can expect their first ovulation sooner [53]. In this study, important variations occurred in the age at which the onset of puberty was experienced; in some cases this was very different from the onset at 11 months-old, as previously cited for this species [51].

Changes to the onset of puberty can be triggered by different factors. The rapid weight gain experienced by animals in captivity [53,54], which increases leptin levels in the blood [55-58], can anticipate the onset of puberty. Similarly, the stress of captivity can delay puberty because of the interference of glucocorticoids in the gonadal axis [59-61].

Among the females that experienced puberty earlier (between 8 and 10 months), only one was pure (P2); the other were hybrids and they eventually cycled. In contrast, the hybrid H5 and the pure females P1 and P3 experienced the onset of puberty at 14 months-old. 


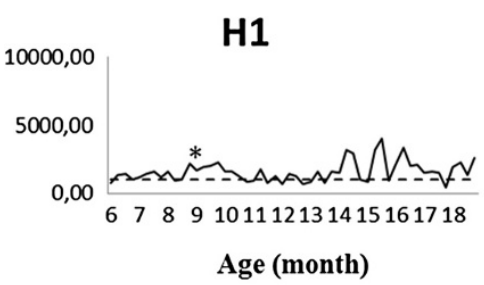

H3

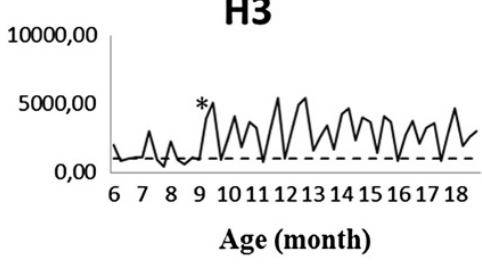

H5

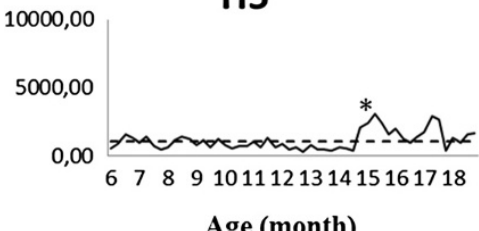

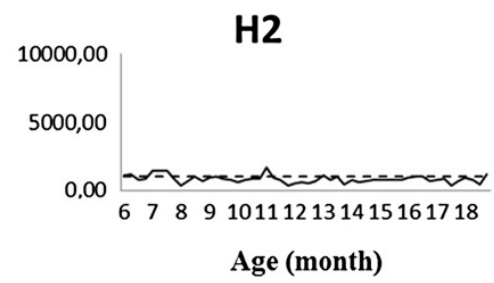

H4

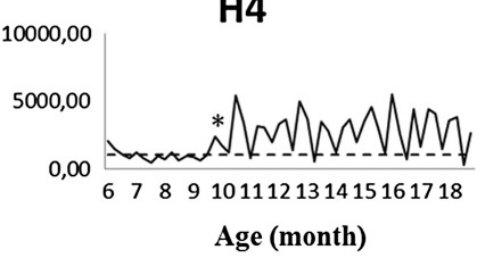

Female $\mathrm{H} 2$ lacked an ovulation cycle, results which can indicate sterility, particularly sterility associated with the lack of ovarian structures. This absence of ovarian structures was also observed in the female H1. The progenitors of females $\mathrm{H} 1$ and $\mathrm{H} 2$ are carriers of complex chromosome rearrangements $(\delta \mathrm{Pr}$ : one pericentric inversion; + Ju: one centric fusion and three tandem-fusion translocations).

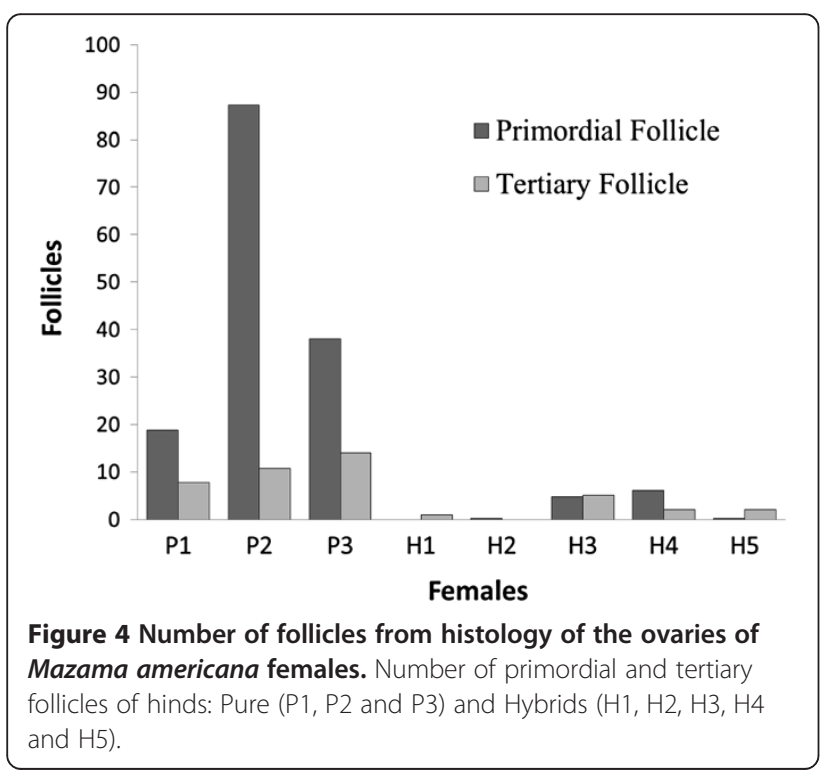

Histological sections from the other female hybrids (H3, H4 and H5) presented germ cells (primordial follicles), though the average number of these structures was lower compared with pure females. Thus, the number of ovarian structures indicates subfertility (H3; H4 and $\mathrm{H} 5)$ or sterility ( $\mathrm{H} 1$ and $\mathrm{H} 2)$ in the hybrid hind studied. The ovarian activity determined in the histological evaluation is related to the response to the superovulation treatment performed on the females; for this reason, a large number of tertiary follicles were obtained, particularly from the pure females.

As expected, the rates of oocyte retrieval in vivo, even following FSH treatment, were lower in hybrid females than in pure females. These results reflect a satisfactory response to the superovulation protocol used. In wild ruminants, the rates of oocyte retrieval are similar: $9.3 \pm$ 1.7 oocytes were retrieved from the species Gazella dama mhorr [62], and $3.21 \pm 0.51$ were retrieved from the species Cervus elaphus [63]. For the species M. gouazoubira, an average of $10.4 \pm 1.1$ follicles was observed in each hind [64]. In the last study, the same superovulation protocol was used, though oocyte aspiration was not performed.

High rates of cleavage blocking and low rates of embryo production are both common in in vitro fertilization studies on ruminants, particularly among wild species (Gazella dama mhorr [62], Cervus nippon and Cervus elaphus [65]), and these factors seem to be related to inadequate medias for development in vitro [65-68]. Thus, it is likely 


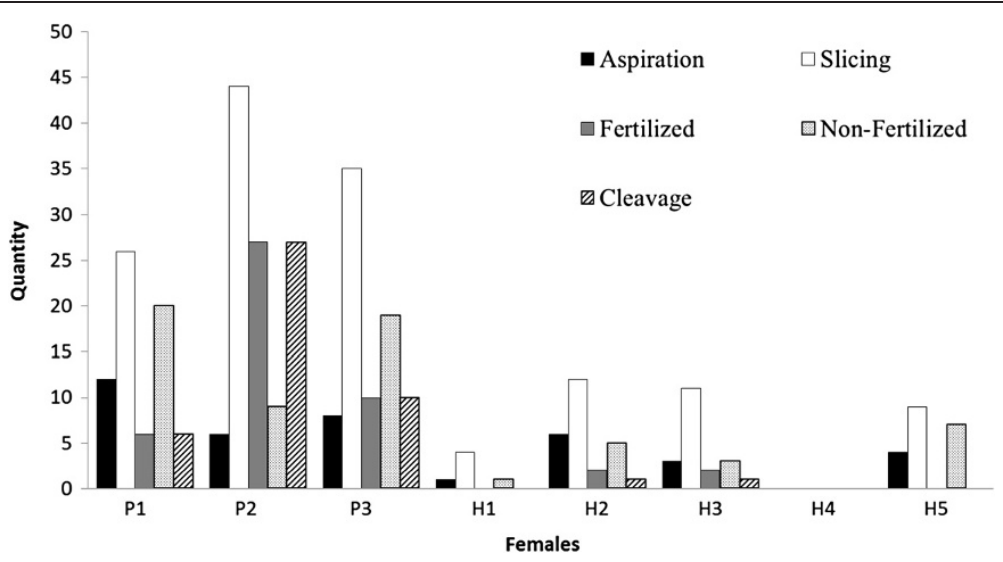

Figure 5 The total amount of structures obtained from Mazama americana females. Structures obtained by in vivo aspiration and in vitro embryo production ( $\mathrm{P}$ - pure females and $\mathrm{H}$ - hybrids females). Aspiration: The total amount of oocytes obtained by in vivo aspiration. Slicing: The total amount of oocytes obtained using the slicing process. Fertilized: The total amount of embryos fertilized in vitro. Non-fertilized: The total amount of embryos not fertilized in vitro. Cleavage: The total amount of embryos that underwent cleavage (2-16 cells).

that embryonic development up to the morula stage in pure females may be due to these factors, while the blocking of embryos in hybrid females during the initial stages of development is primarily related to the chromosomal imbalance of the embryos.

If the oocyte is not fertilized, the mechanism that initiates cleavage may be activated and oocyte division occurs even in the absence of fertilization; for cleavage to continue, the genome of the embryo must be activated. In mice, it has been reported that genome activation occurs during the second round of cell division [69]. In bovine, activation occurs later, between the two- and eightcell stage. In sheep and goats, activation occurs between the eight- and 16-cell stage [70]. There are no studies on gene activation in embryos from Cervidae; therefore, the blocking of embryos from hybrid females before the morula stage (between one and 12 cells) could be related to division by parthenogenetic activation or to failed embryonic genome activation. One of the factors that cause embryonic genome activation to fail is chromosome imbalance.

The high percentage of unfertilized oocytes in hybrid females could be due to a failure during the maturation stage. Incompetent oocytes are deficient in the amount of mRNA necessary to promote nuclear and cytoplasmic maturation. This deficiency impedes the penetration of spermatozoa and, consequently, embryonic development [71]. A study of the synaptonemal complex in fetuses from female hybrids of different species of wallabies determined irregularities in chromosome pairing during the first phase of meiosis. During this phase, unpaired regions and multiple bonds (polyvalence) were identified, among other irregularities [72]. This abnormal meiotic division of the oocyte leads to the production of

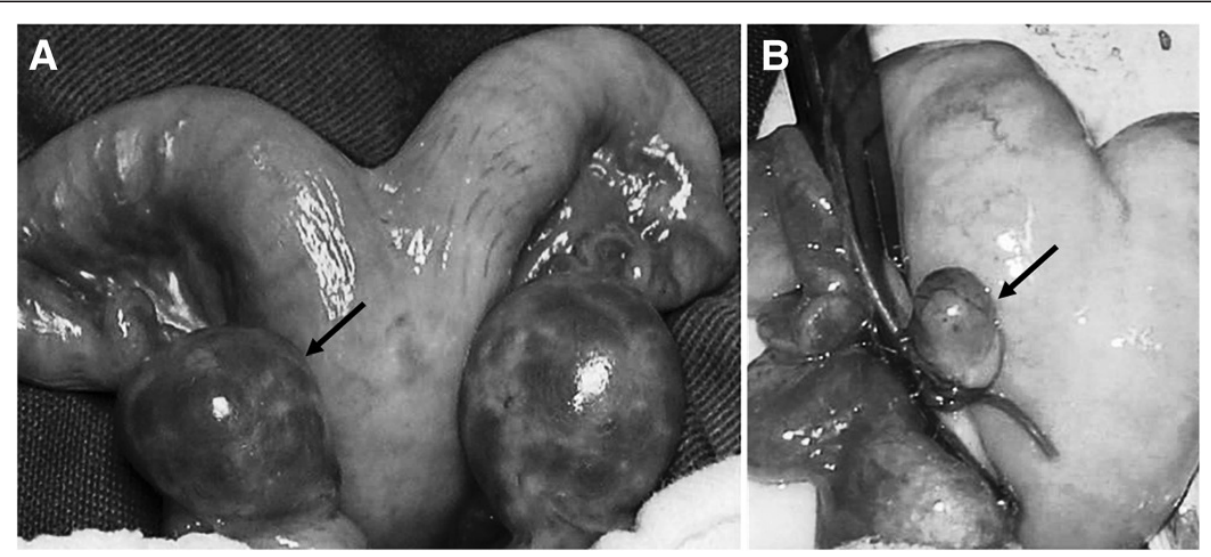

Figure 6 Superovulation response. A - The ovary of pure female P3, which responded to superovulation treatment with follicular development (arrow). B - The ovary of female $\mathrm{H} 1$, which did not respond to superovulation treatment (arrow). 
genetically imbalanced gametes that are unable to continue meiosis or produce the amount of mRNAs necessary for their maturation and the development of reproductive abilities; for this reason, embryonic production in hybrids fails.

\section{Post-zygotic reproductive isolation}

The data obtained in this study makes it possible to draw certain conclusions regarding the reproductive abilities of pure females and the presence of subfertility and sterility in hybrids. Specimens that were the product of crossings between females from Lineage B ( $\mathrm{Pr}$ and $\mathrm{Ca}$ ) and males from Lineage $\mathrm{A}$ (Ju and Ro) presented subfertility, while those that were produced from $\rho \mathrm{A} x{ }^{\lambda} \mathrm{B}$ crossings were almost completely sterile. The females H1 and $\mathrm{H} 2\left({ }^{\circ} \mathrm{Ju} \mathrm{x}{ }^{\top} \mathrm{Pr}\right)$ were sterile, and were the product of progenitors that carried five chromosomal rearrangements: one pericentric inversion, one centric-fusion translocation, and three tandem-fusion translocations. The female H3 $(\circ \operatorname{Pr} \mathrm{x} \quad \mathrm{J} \mathrm{Ju})$ was subfertile, even though the differences between her progenitors involved the same chromosomal rearrangements as the females $\mathrm{H} 1$ and $\mathrm{H} 2$.

The other two females that were subfertile were $\mathrm{H} 4$

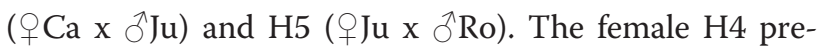
sented the greatest chromosomal difference among the parental cytotypes: one pericentric inversion, one centric fusion and four tandem fusions. The parental cytotypes of female $\mathrm{H} 5$ differ by only one tandem fusion. Even though they are carriers of a heterozygous centric fusion involving the same chromosome pairs, female H5 did not inherit this centric fusion from its progenitors. Thus, its subfertility, detected by reproductive parameters, is related to the difference that the tandem fusion generates between the Ju and Ro cytotypes. This type of rearrangement seems to have an important role in the origin of fertility problems and in the reproductive isolation of several species [19-23].

The accumulation of chromosomal rearrangements leads to infertility due to the death of germ cells, which in turn is due to failures during meiotic pairing $[14,73,74]$. This conclusion seems to be the most likely explanation for the reproductive impairment observed in the female hybrids. In hybrids, the chromosomal rearrangements (pericentric inversion, centric-fusion translocations and tandem-fusion translocations) are heterozygous and could be the cause of the chromosome imbalance that led to subfertility and sterility $[14,75]$. The accumulation of chromosomal rearrangements that are involved in the differentiation between Lineages A and B of M. americana may be the cause of the reproductive isolation identified in our experiment.

Because the cytotypes were geographically isolated [2], chromosomal differentiation between the populations seems to have occurred allopatrically [76]. Chromosome fragility and a high rate of chromosomal rearrangements are probably involved in the karyotype evolution of Cervidae and both of these would explain the system of Mazama americana cytotypes [77]. According to Duarte et al. [4], the divergence of the most distant lineages of $M$. americana most likely occurred 2.5 million years ago; a relatively short amount of time for two such karyotypically different species to develop. Two species that diverged from this branch were M. bororo and M. nana, with $2 \mathrm{n}$ of 32 and 38 , respectively [3,7]. Thus, chromosomal rearrangements seem to be the most important and efficient mechanism of speciation in this group to achieve the generation of reproductive isolation after such a short period of time.

Villena and Sapienza [78] argued that karyotype evolution in mammals has occurred mainly through the nonrandom segregation of chromosomes during meiosis in the oocyte. They affirmed that factors that regulate female meiosis play a role in the fixation of certain chromosomal rearrangements. In the case of the genus Mazama, the main rearrangements were those that reduced the diploid number in populations, such as centric-fusion and tandemfusion translocations, which are both present in large quantities during the differentiation between the cytotypes of $M$. americana $[12,79]$.

In 2008, Duarte et al. [4] evaluated the genetic distance between the $M$. americana cytotypes. They suggested that the separation of the cytotypes may have occurred at the end of the Pliocene, after the great migration of the ancestral forms of these species, which came from North America. After the isolation of the populations, both genetic and cytogenetic diversification occurred. Based on cytogenetic analyses, Abril et al. [12] suggested the differentiation of two clades of the species $M$. americana, which is supported by molecular analyses of mitochondrial DNA. These analyses revealed that the Rondônia and Juína cytotypes compose the A clade, with a smaller chromosomal number, and that the Paraná, Carajás, Jarí and Santarém cytotypes compose the B clade, with a larger diploid number. Despite chromosomal and genetic differences, the populations maintained the same phenotype, and can therefore be considered as cryptic species [80].

All of the crossings performed between Lineages A and $\mathrm{B}$ resulted in reproductive isolation, supporting the separation of these two lineages into at least two species. Since few crossings of deer with distinct karyotypes were obtained from the same chromosomal lineage (one female; $\mathrm{H} 5$ ), it is difficult to prove the existence of reproductive isolation within chromosome lineages, despite the fact that the hind produced was subfertile.

The high degree of chromosomal divergence in $M$. americana causes an important taxonomic problem. Rossi's morphological studies [11] did not identify any significant differences between populations of $M$. americana. Thus, 
though there are relevant and consistent chromosomal and molecular differences among the populations [12], including the well-established case of reproductive isolation, these differences are not reflected in morphological differences. This inconsistency makes it difficult to identify species without using genetic methods.

Despite the existence of well-defined cytotypes that have been proven to be reproductively isolated, questions remain regarding the taxonomic level of the closest cytotypes, such as Paraná and Carajás, or even Juína and Rondônia. These uncertainties cause problems that are reflected in conservation and raise the question whether each cytotype should be considered independent from a taxonomic perspective. A larger sample must be collected, and more studies, particularly concerning the existence of reproductive isolation among closely related cytotypes must be performed so that the correct management and conservation decisions can be made. One of the cytotypes, that which is found in the Atlantic Forest region of South America, could be considered the most threatened of the cervid species in the Americas if it is considered to be from a different taxon than the remaining red brocket deer.

\section{Conclusion}

In this study, we verified that two of the six chromosome variants that exist within $M$. americana (Lineage A- Paraná and Lineage B- Juína) possess an efficient mechanism of post-zygotic reproductive isolation, which involves infertility or subfertility of the hybrid. Once the true impossibility of gene flow between the lineages is identified, more concrete discussions on modifications to the taxonomy of this species can be initiated. In light of the results of this study, combined with previous studies, both lineages may be considered as cryptic species that present the same phenotype. Populations with similar karyotypes must be evaluated more carefully, since there is a reasonable likelihood that they are also distinct species. Chromosomal changes have proven to be an efficient and powerful mechanism in the isolation of populations and in the formation of species in the genus Mazama.

\section{Methods}

The present study was approved by the Animal Ethics and Welfare Committee (Comitê de Ética e Bem-estar Animal, CEBEA) of the School of Agricultural and Veterinary Sciences (Faculdade de Ciências Agrárias e Veterinárias, FCAV) of São Paulo State University (UNESP), Jaboticabal, SP, Brazil.

\section{Animals}

The females used in the experiment were generated by crossing deer from the species $M$. americana. The animals belonged to the Deer Research and Conservation Center (Núcleo de Pesquisa e Conservação de Cervídeos - NUPECCE) of the Department of Animal Science of the FCAV-UNESP in Jaboticabal, Sao Paulo, Brazil. The parents were karyotyped and identified as members of different cytotypes: Juína, or Ju $(2 \mathrm{n}=43-44$ 우 $/ 44-45 \hat{\jmath}+3-6 \mathrm{~B}$ and FN = 48); Rondônia, or Ro $(2 \mathrm{n}=42+/ 43 \hat{\jmath}+3-5 \mathrm{~B}$ and $\mathrm{FN}=46)$; Paraná, or $\operatorname{Pr}(2 \mathrm{n}=52+/ 53 \hat{\jmath}+3-4 \mathrm{~B}$ and $\mathrm{FN}=56)$; and Carajás, or $\mathrm{Ca}\left(2 \mathrm{n}=50\right.$ + $/ 51 \mathrm{O}^{-}+3-4 \mathrm{~B}$ and $\left.\mathrm{FN}=54\right)$. The deer with the most similar karyotypes were considered to be from the same chromosome lineage. Thus, two lineages were established: Linage A) Ju and Ro cytotypes and Lineage B) Pr and Ca cytotypes.

Only female offspring were used in this study. From the crossings between specimens of the same cytotype (considered "pure," or P), two females from the Juína cytotype were obtained (P1 and P2), as well as one female from the Rondônia cytotype (P3). From the crossings between specimens with different cytotypes (considered hybrids, H) five females were obtained: crossings between the Juína and Paraná cytotypes ( $\mathrm{H} 1$ and $\mathrm{H} 2=\delta \mathrm{Pr} \mathrm{x}$ ๆ Ju; $\left.\mathrm{H} 3=\delta^{\top} \mathrm{Ju} \mathrm{x}+\mathrm{Pr}\right)$, Carajás and Juína $\left(\mathrm{H} 4=\delta^{\lambda} \mathrm{Ju} \times \mathrm{x}+\mathrm{Ca}\right)$ and Juína and Rondônia $\left(\mathrm{H} 5={ }^{\lambda} \mathrm{Ro} \times \mathrm{P}\right.$ Ju).

\section{Measurement of fecal progesterone metabolites (FPM) levels \\ Feces collection}

The feces samples used for measuring hormones were collected over the course of a year, with seven days between each collection. Collections began when the specimens were six months-old, and they were completed when each hind reached 18 months of age. Collection did not begin until the hind had been weaned (six months of age), because until this period, the fawn remained in the female's stall, which made it difficult to collect individual fecal matter. The samples were stored in plastic bags and maintained at $-20^{\circ} \mathrm{C}$ until processing was begun.

\section{Processing the samples}

The samples were dried in an oven at $56^{\circ} \mathrm{C}$ for approximately $72 \mathrm{~h}$ and then pulverized $[49,81]$. The metabolites were extracted from the fecal samples as described by Graham [50]. The supernatant was separated and stored at $-20^{\circ} \mathrm{C}$ until the measurements were performed.

\section{Enzyme immunoassay (EIA)}

For the measurements determined by an EIA (Multiskan MS, Labsystem, Helsinki, Finland), CL425 monoclonal antibody (CJ Munro, University of California, Davis, USA) was used for progestogens [50]. All fecal extracts were diluted (1:256) in a dilution buffer and measured in duplicate. The hormone measurements were validated using the process described by Brown [82]: (1) parallelism 
between serial dilutions from a pool of fecal extracts and a standard curve; and (2) significant recovery of exogenous progesterone added to fecal extracts $(y=-0.0231 x+2.5316$ and $\mathrm{R}^{2}=0.9797$ ). The interassay coefficient of variation for the two separate controls was 11 (30\% binding) and 19.6 (70\% binding) for metabolites of fecal progesterone. All of the data collected on the feces were expressed based on its dry weight.

\section{Estrus synchronization, superovulation and surgical procedure}

At 18 months of age, the females were submitted to the estrus synchronization and superovulation protocol. Estrus was synchronized with an intravaginal progesterone insert (CIDR - Controlled Internal Drug Release ${ }^{\circ}$ - Pfizer ${ }^{\circ}$, USA) for 8 days, followed by intramuscular application of $0.25 \mathrm{~mL}$ of estradiol benzoate (Estrogin, Farmavet Produtos Veterinarios Ltda, Brazil) at the moment the implant was inserted (D0). On the day four (D4) of implantation of the progesterone insert, the administration of a follicle stimulating hormone (FSH) (Folltropin ${ }^{\circ} \mathrm{V}$, Tecnopec, Canada) was initiated: $130 \mathrm{mg}$ divided into 8 equal doses that were applied every 12 hours [83]. Eight days after beginning treatment (D8), the specimens were submitted to a laparotomy in order to perform follicular aspiration of an ovary in vivo and an ovariectomy of the ovary that was contralateral to the one that had been aspirated. To perform the surgery, the hind were fasted for $24 \mathrm{~h}$ and were then anesthetized with $5.0 \mathrm{mg} / \mathrm{Kg}$ of ketamine hydrochloride (Vetaset ${ }^{\oplus}$ - Fort Dodge, Brazil), $0.3 \mathrm{mg} / \mathrm{Kg}$ of xylazine hydrochloride (Rompum ${ }^{\circ}$ - Bayer, Brazil), and $0.5 \mathrm{mg} / \mathrm{Kg}$ of midazolam (Dormonid ${ }^{\circ}$ - Roche, Brazil) and maintained under isoflurane (Forane $e^{\circ}$ Abbott, Brazil) during the procedure. After the surgery was completed, the intravaginal insert $\left(\mathrm{CIDR}^{\circ}\right)$ was removed.

\section{In vivo oocyte aspiration}

The process of in vivo aspiration was performed with a number 22 intravenous infusion device $\left(\mathrm{BD}^{\circ}\right)$ attached to a $10-\mathrm{mL}$ syringe. The aspirated follicular fluid was maintained in a PBS solution completed with Heparin $(10 \mathrm{UI} / \mathrm{mL})$. The solution had been previously heated to $37^{\circ} \mathrm{C}$ and the fluid was maintained at this temperature until the onset of in vitro production (IVP). The ovary that was removed was stored in the same solution, and was later divided into two equal parts: one was used to obtain oocytes by slicing, and the other for a histological exam.

\section{Ovarian histology}

The half of the ovary used for histology was maintained in Bouin solution for fixation. In order to prepare the histological slides, $5 \mu \mathrm{m}$ sections were made and the slides received two types of stains: HE and Mason's Trichrome stain. The histological sections were viewed under a light microscope and the morphology of their structures were analyzed descriptively. The number of structures in the entire histological sections was determined using the Axio Vision program, version 4.8.2.

\section{Semen collection and preparation for in vitro fertilization (IVF)}

The semen donors were the fathers of the female donors of the oocytes. Semen collection for IVF was performed using electroejaculation. The semen collected was prediluted in Tris-yolk $[84,85]$ and its motility, vigor, and concentration were analyzed. Next, the concentration was adjusted to $50 \times 10^{6}$ spermatozoa $/ \mathrm{mL}$ and the semen was stored in $0.25-\mathrm{mL}$ straws and frozen in a TK-3000 portable medical refrigerator (TK Equipamentos para Reprodução, Brazil). It was maintained at $-196^{\circ} \mathrm{C}$ until IVF was performed. Later, one straw was defrosted to $35^{\circ} \mathrm{C}$ for 20 seconds, and the semen was deposited into a 2-mL tube containing a discontinuous Percoll Gradient (Biotech Pharmacy, Sweden) of 90\% and 45\% [86] and inserted in drops of an IVF medium (TL-Semen, $500 \mathrm{mg}$ amikacin sulfate, SOF, PHE, Heparin and $176 \mathrm{UI} / \mathrm{mg}$ and serum from sheep in estrus).

\section{In vitro production of embryos}

The portion of the ovary used to obtain oocytes was sliced into a PBS solution completed with Heparin (10 UI/ml) and heated to $37^{\circ} \mathrm{C}$. Next, the solutions obtained from slicing and from in vivo aspiration were analyzed using a stereomicroscope in order to classify the oocytes. The classification process followed the parameters determined for bovine reproduction [87]. Those that were classified as being of higher quality were forwarded for maturation in vitro (TCM-199; SFB10\%; $0.20 \mathrm{mM}$ pyruvate; $83.3 \mu \mathrm{g} / \mathrm{mL}$ amikacin sulfate; $1.0 \mu \mathrm{g} / \mathrm{mL} \mathrm{FSH}$; and $50 \mu \mathrm{g} / \mathrm{mL} \mathrm{hCG}$ ) for $27 \mathrm{~h}$ [88]. The oocytes were inserted in the IFV medium with semen, and after $18 \mathrm{~h}$ of fertilization, the potential embryos were transferred to culture medium (Medium of SOF; 2,5\% SFB; $5 \mathrm{mg} / \mathrm{mL}$ $\mathrm{BSA})$. On day 10, the pre-embryos were stained with Hoechst 33342 in order to determine the presence or absence of pronuclei and blastomeres, which indicate fertilization and embryonic development, respectively. To achieve this, the oocytes/embryos were transferred into drops (made up of a blocking solution, $10 \mu \mathrm{L}$ of Hoechst 33342 and glycerol) on a slide and covered with a cover slip. The sides of the slide were sealed with enamel. After $2 \mathrm{~h}$, the analyses were completed under an epifluorescence microscope (excitation filter BP 330$385 \mathrm{~nm}$ and barrier filter BA 420), and the samples were photographed using a digital camera (Olympus ${ }^{\oplus} \mathrm{C}-5060$, 5.1 megapixels). 


\section{Results analysis}

Measurements of FPM

The profiles obtained by FPM measurements were analyzed following the process described by Graham [89]. Data concerning the concentration of all of the female samples were combined to calculate the overall mean FPM concentration. Values that were greater than this mean plus 1.75 SD (standard deviation) were temporarily removed from the data. The mean was recalculated and the process of removing concentrations was repeated until no value exceeded the mean plus 1.75SD. The remaining data were considered to represent the baseline FPM concentrations. The onset of the estrous cycles was considered to be when the FPM concentrations were greater than the baseline mean and remained high for more than two weeks, followed by a drop to baseline levels. The onset of puberty was considered to be when the beginning of the first cycle was evident.

\section{Histological structure count}

The results are presented as the mean \pm SEM (standard error) of the analysis of three histological sections for each hind. The results from the hybrid females and the "pure" females were descriptively compared.

\section{Response to superovulation}

The superovulation process was evaluated based on the amount of oocytes obtained from the follicular aspiration of both the hybrid and pure females (mean $\pm \mathrm{SD}$ ), and the results were descriptively compared.

\section{In vitro production of embryos}

Production was evaluated by observing the nuclear Hoechst 33342 staining of the oocytes and embryos. The structures that presented nuclei in different phases of meiosis were considered unfertilized, while the structures that presented pronuclei or blastomere nuclei were considered fertilized. Degenerated oocytes/embryos, fragmented oocytes/embryos, or oocytes/embryos with the presence of too many cumulus cells that prevented the visualization of the nuclei were considered inconclusive. The number of fertilized and unfertilized structures is presented as a percentage, and the results from the hybrid and the pure females were compared.

\section{Availability of supporting data}

The data sets supporting the results of this article are available in the Knowledge Network for Biocomplexity repository, knb.312.1. (http://knb.ecoinformatics.org/m/ \#view/knb.312.1).

\section{Competing interests}

The authors declare that there are no competing interests.

\section{Authors' contributions}

MSC conceived and designed the study, participated in the acquisition, analysis and interpretation of data and drafted the manuscript. MBS, WA and ESZ participated in the study design, acquisition, analysis and interpretation of data and helped to draft the manuscript. JMBD participated in the study design and coordination, and helped to draft the manuscript. All authors read and approved the final manuscript.

\section{Acknowledgments}

The authors would like to thank Roberta Vantini of the Fertilization Laboratory (Laboratório de Fecudação) in vitro of the Animal Reproduction Department of the School of Agricultural and Veterinary Sciences of São Paulo State University (FCAV-UNESP) in Jaboticabal, São Paulo, Brazil, for her assistance during the IVP procedures and Orandi Mateus of the Laboratory of Histology and Embryology (Laboratório de Histologia e Embriologia) of the Animal Morphology and Physiology Department of the FCAV-UNESP for his assistance during histology slide preparation. The authors are grateful for the financial support provided by FAPESP (São Paulo Research Foundation) and CAPES (Coordination for the Improvement of Higher Education Personnel).

\section{Author details}

${ }^{1}$ NUPECCE - Núcleo de Pesquisa e Conservação de Cervídeos, Departamento de Zootecnia, FCAV -Faculdade de Ciências Agrárias e Veterinárias, UNESP_ Universidade Estadual Paulista, CEP 14884-900, Jaboticabal, SP, Brazil. ${ }^{2}$ Programa de Pós-graduação em Medicina Veterinária, Reprodução Animal, FCAV, UNESP, CEP 14884-900 Jaboticabal, SP, Brazil. 'Laboratory of Embryology and Biotechniques of Reproduction, Faculty of Veterinary Medicine, Postal 15004, 91501-970 Porto Alegre, RS, Brazil.

Received: 11 February 2013 Accepted: 24 February 2014 Published: 4 March 2014

\section{References}

1. Abril W, Sarria-Perea JA, Vargas-Munar DSF, Duarte JMB: Chromosome evolution. In Neotropical Cervidology, Biology and Medicine of Latin American Deer. 1st edition. Edited by Duarte JMB, Gonzáles S. Jaboticabal: FUNEP; 2010:18-26.

2. Duarte JMB, Jorge W: Chromosomal polymorphism in several population of deer (genus Mazama) from Brazil. Archivos de Zootecnia 1996, 45:281-287.

3. Duarte $J M B$, Jorge $W$ : Morphologic and cytogenetic description of the small red brocket (Mazama bororo Duarte, 1996) in Brazil. Mammalia 2003, 67(Suppl 3):403-410.

4. Duarte JMB, González S, Maldonado JE: The surprising evolutionary history of South American deer. Mol Phylogenet Evol 2008, 49:17-22

5. Neitzel H: Chromosome Evolution of Cervidae: Karyotypic and Molecular Aspects. In Cytogenetics, Basic and Applied Aspects. Edited by Obe G, Basler A. Berlin: Springer Verlag; 1987:91-112

6. Taylor KM, Hungerford DA, Snyder RL: Artiodactyl Mammals: Their Chromosome Cytology In Relation To Patterns Of Evolution. In Comparative Mammalian Evolution. Edited by Benirschke K. Berlin: Springer Verlag; 1969:346-356.

7. Abril W, Duarte JMB: Chromosome polymorphism in the Brazilian dwarf brocket deer Mazama nana (Mammalia, Cervidae). Genet Mol Biol 2008, 31(Suppl 1):53-57.

8. Jorge W, Benirschke K: Centromeric heterochromatin and G-banding of the red brocket deer Mazama americana temama (Cervoidea, Artiodactyla) with probable non-Robertsonian translocation. Cytologya 1977, 42:711-721.

9. Sarria-Perea JA: Comparação Entre Alguns Citótipos De Mazama Americana (Artiodactyla; Cervidae): Quão Grande É A Diferença Entre Eles. In Master Tesis. Universidade Estadual de São Paulo, Departamento de Zootecnia; 2004

10. Varela DM, Trovati RG, Guzmán KR, Rossi RV, Duarte JMB: Red Brocket Deer Mazama Americana (Erxleben 1777). In Neotropical Cervidology, Biology and Medicine of Latin American Deer. 1st edition. Edited by Duarte JMB, Gonzáles S. Jaboticabal: FUNEP; 2010:151-159.

11. Rossi RV: Taxonomia de Mazama Ranfinesque, 1817 do Brasil (Artyodactyla, Cervidae). In Phd Thesis. Universidade de São Paulo: Instituto de Biociências; 2000. 
12. Abril W, Carnelossi EAG, Gonzales S, Duarte JMB: Elucidating the evolution of the red brocket deer Mazama americana complex (Artiodactyla; Cervidae). Cytogenet Genome Res 2010, 128:177-187.

13. Coghlan A, Eichler EE, Oliver SG, Paterson AH, Stein L: Chromosome evolution in eukaryotes: a multi-kingdom perspective. Trends Genet 2005, 21(Suppl 12):673-682.

14. Riesenberg L: Chromosomal rearrangements and speciation. Trends Ecol Evol 2001, 16(Suppl 7):351-358.

15. Switonski M, Stranzinger G: Studies of synaptonemal complexes in farm mammals - a review. Am Genet Assoc 1998, 89:473-480.

16. King M: Species Evolution: The Role of Chromosome Change. Cambridge: University Press; 1995.

17. Baker RJ, Bickham JW: Speciation by monobrachial centric fusions. Proc Natl Acad Sci 1986, 83:8245-8248.

18. Merico V, Giménez MD, Vasco C, Zuccotti M, Searle JB, Hauffe HC, Garagna S: Chromosomal speciation in mice: a cytogenetic analysis of recombination. Chromosome Res 2013, 21:523-533.

19. Yang F, O'Brien PCM, Wienberg J, Ferguson-Smith MA: A reappraisal of the tandem fusion theory of karyotype evolution in the Indian muntjac using chromosome painting. Chromosome Res 1997, 5:109-117.

20. Pinheiro LEL, Carvalhoi TB, Oliveira DAA, Popescu CP, Basrur PK: A 4/21 tandem fusion in cattle. Hereditas 1995, 122:99-102.

21. Di Berardino D, lannuzzi L: Chromosome banding homologies in swamp and murrah buffalo. J Hered 1981, 72(Suppl 3):183-188.

22. Hansen KM: Bovine tandem fusion and fertility. Hereditas 1969, 63:453-454

23. Liming S, Yingying $Y$, Xingsheng D: Comparative cytogenetic studies on the red muntjac, Chinese muntjac, and their F1 hybrids. Cytogenet Cell Genet 1980, 26(Suppl 1):22-27.

24. Feder $J \mathrm{~L}$, Nosil P: Chromosomal inversions and species differences: when are genes affecting adaptive divergence and reproductive isolation expected to reside within inversions? Evolution 2009, 63(Suppl 12):3061-3075.

25. Noor MAF, Grams KL, Bertucci LA, Reiland J: Chromosomal inversions and the reproductive isolation of species. Proc Natl Acad Sci 2001, 98:12084-12088.

26. Hoffman AA, Riesenberg LH: Revisiting the impact of inversions in evolution: from population genetic markers to drivers of adaptive shifts and speciation? Ann Rev Ecol Evol Syst 2008, 39:21-42.

27. Hale DW: Heterosynapsis and suppression of chiasmata within heterozygous pericentric inversions of the Sitka deer mouse. Chromosoma 1986, 94:425-432.

28. Setterfield LA, Mahadevaiah S, Mittwoch U: Chromosome pairing and germ cell loss in male and female mice carrying a reciprocal translocation. J Reprod Fertil 1988, 82:369-379.

29. Akhverdyan M, Fredga KEM: Studies of female in wood lemmings with different sex chromosome constitutions. J Exp Zool 2001, 290:504-516.

30. Thomsen PD, Schauser K, Bertelsen MF, Vejlsted M, Grondahl C, Christensen K Meiotic studies in infertile domestic pig-babirusa hybrids. Cytogenet Genome Res 2011, 132:124-128.

31. Benirschke K, Sullivan M: Corporea lutea in proven mules. Fertil Steril 1966, 17(Suppl 1):24-33.

32. Taylor MJ, Short RV: Development of germ cells in the ovary of the mule and hinny. J Reprod Fertil 1973, 32:441-445.

33. West JD, Frels WI, Chapman VM: Mus musculus x Mus caroli hybrids: mouse mules. J Hered 1978, 69:321-326.

34. Rong R, Chandley AC, Song J, McBeath S, Tan PP, Bai Q, Speed RM: A fertile mule and hinny in China. Cytogenet Cell Genet 1988, 47:134-139.

35. Close RLE, Bell JN: Fertile hybrids in two genera of wallabies: petrogaleand thylogale. J Hered 1997, 88(Suppl 5):393-397.

36. Pickard AR, Abáigar T, Green DI, Holt W, Cano M: Hormonal characterization of the reproductive cycle and pregnancy in the female mohor gazelle (Gazella dama mhorr). Reproduction 2001, 122:571-580.

37. Schwartz CC, Monfort SL, Dennis PH, Hundertmark KJ: Fecal progestagen concentration as an indicator of the estrous cycle and pregnancy in moose. J Wildl Manage 1995, 59(Suppl 3):580-583.

38. Wasser SK, Velloso AL, Rodden MD: Using fecal steroids to evaluate reproductive function in female maned wolves. J Wildl Manage 1995, 59(Suppl 4):889-894.

39. Schwarzenberger F, Rietschel W, Vahala J, Holeckova D, Thomas P, Maltzan J, Baumgartner K, Schaftenaar W: Fecal progesterone, estrogen, and androgen metabolites for noninvasive monitoring of reproductive function in the female Indian rhinoceros, Rhinoceros unicornis. Gen Comp Endocrinol 2000, 119:300-307.

40. Pereira RJG, Polegato BF, Souza S, Negrão JA, Duarte JMB: Monitoring ovarian cycles and pregnancy in brown brocket deer (Mazama gouazoubira) by measuremant of fecal progesterone metabolites. Theriogenology 2006, 65:387-399.

41. Zanetti ES, Duarte JMB, Polegato BF, Garcia JM, Canola JC: Assisted Reproductive Technology. In Neotropical Cervidology, Biology and Medicine of Latin American Deer. 1st edition. Edited by Duarte JMB, Gonzáles S. Jaboticabal: FUNEP; 2010:255-270.

42. Zanetti ES, Duarte JMB: Comparison of three protocols for superovulation of brown brocket deer (Mazama gouazoubira). Zoo Biol 2011, 30:1-14.

43. Krepschi VG, Polegato BF, Zanetti ES, Duarte JMB: Fecal progestins during pregnancy and postpartum periods of captive red brocket deer (Mazama Americana). Anim Reprod Sci 2013, 137(Suppl 1-2):62-68.

44. Matzuk MM, Burns KH, Viveiros MM, Eppig JJ: Intercellular communication in the mammalian ovary: oocytes carry the conversation. Science 2002 296:2178-2180.

45. Bettegowda A, Smith GW: Mechanisms of maternal mRNA regulation: implications for mammalian early embryonic development. Front Biosci 2007, 12:3713-3726.

46. Bettegowda A, Lee K, Smith GW: Citoplasmic and nuclear determinations of the maternal-to-embrionic transition. Reprod Fert Dev 2008, 20:45-53.

47. Hirata S, Mori Y: Monitoring reproductive status by fecal progesterone analysis in ruminants. J Vet Med Sci 1995, 57(Suppl 5):845-850.

48. Schwarzenberger F, Möstl E, Palme R, Bamberg E: Faecal steroid analysis for non-invasive monitoring of reproductive status in farm, wild and zoo animals. Anim Reprod Sci 1996, 42(Suppl 1-4):515-526.

49. Yamauchi K, Hamasaki S, Takeuchi Y, Mori Y: Assessment of reproductive status of sika deer by fecal steroid analysis. J Reprod Dev 1997, 43(Suppl 3):221-226.

50. Graham LH, Schwarzenberger F, Möstl E, Galama W, Savage A: A versatile enzyme immunoassay for the determination of progestagens in feces and serum. Zoo Biol 2001, 20:227-236.

51. Wemmer C: Deer. Status Survey and Conservation Action Plan. Switzerland and Cambridge: IUCN/SSC Deer Specialist Group; 1998.

52. Pereira RJG: Male Reproduction. In Neotropical Cervidology, Biology and Medicine of Latin American Deer. 1st edition. Edited by Duarte JMB, Gonzáles S. Jaboticabal: FUNEP; 2010:39-50.

53. Sadleir RMFS: Reproduction of Female Cervids. In Biology and Management of the Cervidae. Edited by Wemme CM. Washington: Smithsonian Institution Press; 1987.

54. Kennedy GC, Mitra J: Body weight and food intake as initiating factors for puberty in the rat. J Physiol 1963, 166:408-418.

55. Kiess W, Blum WF, Aubert M: Leptin, puberty and reproductive function: lessons from animal studies and observations in humans. Eur J Endocrinol 1998, 138:26-29.

56. González RR, Símon C, Caballero-Campo P, Norman R, Chardonnens D, Devoto L, Bischof P: Leptin and reproduction. Hum Reprod Update 2000, 6(Suppl 3):290-300.

57. Caprio M, Fabbrini E, Isidori AM, Fabbri A, Aversa A: Leptin in reproduction. Trends Endocrinol Metab 2001, 12(Suppl 2):65-72.

58. Garcia MR, Amstalden M, Williams SW, Stanko RL, Morrison CD, Keisler DH, Nizielski SE, Williams GL: Serum leptin and its adipose genes expression during pubertal development, the estrous cycle, and different seasons in cattle. J Anim Sci 2002, 80:2158-2167.

59. Moberg GP: How behavioral reproduction in stress disrupts the endocrine control of domestic Animals. J Dairy Sci 1991, 74(Suppl 1):304-411.

60. Dobson H, Smith RF: What is stress, and how does it affect reproduction? Anim Reprod Sci 2000, 60:743-752.

61. Breen KM, Billings HJ, Wagenmaker ER, Wessinger EW, Karsch FJ: Endocrine basis for disruptive effects of cortisol on preovulatory events. Endocrinology 2005, 146(Suppl 4):2107-2115

62. Berlinguer F, González R, Succu S, Del Olmo A, Garde JJ, Espeso G, Gomendio M, Ledda S, Roldan ERS: In vitro oocytematuration, fertilization and culture after ovum pick-up in an endangered gazelle (Gazella dama mhorr). Theriogenology 2008, 69:349-359.

63. Asher GW, O'Neill KT, Scott IC, Mockett BG, Pearse AJ: Genetic influences on reproduction of female red deer (Cervus elaphus) (2) Seasonal and genetic effects on the superovulatory response to exogenous FSH. Anim Reprod Sci 2000, 59:61-70. 
64. Zanetti ES: Protocolos De Superovulação Em Veado-Catingueiro (Mazama gouazoubira). In PhD Thesis. UNESP - Universidade estadual Paulista, Faculdade de Ciências Agrárias e Veterinárias, Departamento de Reprodução Animal; 2009.

65. Comizzoli P, Mermillod P, Cognié Y, Chai N, Legendre X, Muget R: Successful in vitro production of embryos in the red deer (Cervus elaphus) and sika deer (Cervus nippon). Theriogenology 2001, 55:649-659.

66. Bainbridge DRJ, Catt SL, Evans G, Jabbour HN: Successful in vitro fertilization on in vivo matured oocytes aspirated laparoscopically from red deer hinds (Cervus elaphus). Theriogenology 1999, 51:891-898.

67. Berg DK, Asher GW: New developments reproductive technologies in deer. Theriogenology 2003, 59:189-205.

68. Locatelli Y, Cogné Y, Vallet JC, Baril G, Verdier M, Poulin N, Legendre X, Mermillod P: Successful use of oviduct epithelial cell coculture for in vitro production of viable red deer (Cervus elaphus) embryos. Theriogenology 2005, 64:1729-1739

69. Nothias J, Majumder S, Kaneko KJ, DePamphilis ML: Regulation of gene expression at the beginning of Mammalian development. J Biol Chem 1995, 270(Suppl 22):22077-22080.

70. Memili E, First NL: Zygotic and embryonic gene expression in cow: a review of timing and mechanisms of early gene expression as compared with other species. Zygote 2000, 8:87-96.

71. Gonçalves PBD, Visintin JA, Oliveira MAL, Montagner MM, Costa LFS: Produção In Vitro De Embriões. In Biotécnicas Aplicadas À Reprodução Animal. Edited by Gonçalves PBD, Figueiredo JR, Freitas VJ. São Paulo: Varela; 2001:195-226.

72. Eldridge MDB, Wilson ACC, Metcalfe CJ, Dollin AE, Bell JN, Johnson PM, Johnston PG, Close RL: Taxonomy of rock-wallabies, Petrogale (Marsupialia: Macropodidae). III Molecular data confirms the species status of the purple-necked rock-wallaby (Petrogale purpureicollis Le Souef). Aust J Zool 2001, 49:323-343.

73. Bhatia S, Shanker V: Chromosome abnormalities in reproductively inefficient goats. Small Ruminant Res 1996, 19:155-159.

74. Villagómez DAF, Pinton A: Chromosomal abnormalities, meiotic behavior and fertility in domestic animals. Cytogenet Genome Res 2008, 120:69-80.

75. Walsh JB: Rate of accumulation of reprodutive isolation by chromosome rearrangements. Am Nat 1982, 120(Suppl 4):510-532.

76. Sene FM: Cada Caso, Um Caso... Puro Acaso: Os Processos De Evolução Biológica Dos Seres Vivos. Sociedade Brasileira de Genética: Ribeirão Preto; 2009.

77. Vargas-Munar DSF, Sarria-Perea JA, Duarte JMB: Different responses to doxorubicin-induced chromosome aberrations in Brazilian deer species. Genet Mol Res 2010, 9(Suppl 3):1545-1549.

78. Villena FP, Sapienza C: Female meiosis drives karyotypic evolution in mammals. Genetics 2001, 159:1179-1189.

79. Fontana F, Rubini M: Chromosomal evolution in Cervidae. Biosystems 1990, 34:157-174

80. Pfenninger M, Schwenk K: Cryptic animal species are homogeneously distributed among taxa and biogeographical regions. BMC Evol Biol 2007, 7:121. http://www.biomedcentral.com/1471-2148/7/121

81. Hamasaki S, Yamauchi K, Ohki T, Murakami M, Takahara Y, Takeuchi Y, Mori Y: Comparison of various reproductive status in sika deer (Cervus nippon) using fecal steroid analysis. J Vet Med Sci 2001, 63:188-195.

82. Brown J, Walker S, Steinman K: Endocrine Manual for the Reproductive Assessment of Domestic and Non-Domestic Species. 2nd edition. Front Royal, VA: Endocrine Research Laboratory, Department of Reproductive Sciences, Conservation and Research Center, National Zoological Park, Smithsonian Institution; 2004

83. Zanetti ES, Duarte JMB: Protocols for Superovulation of Brown Brocket Deer (Mazama Gouazoubira). In 7th International Deer Biology Congress, 1-6 august 2010. Edited by Advances and Challenges in Deer Biology. Chile: Huilo Huilo; 2010:219-220.

84. Duarte JMB, Garcia JM: Tecnologia Da Reprodução Para Propagação E Conservação De Espécies Ameaçadas De Extinção. In Biologia E Conservação De Cervídeos Sul Americanos: Blastocerus, Ozotocerus E Mazama. Edited by Duarte JMB. Jaboticabal: Funep; 1997:228-238.

85. Favoretto SM, Zanetti ES, Duarte JMB: Cryopreservation of red brocket deer semen (Mazama americana): comparison between three extenders. J Zoo Wildlife Med 2012, 43(Suppl 4):820-827.

86. Seneda MM, Esper CR, Garcia JM, Oliveira JA, Vantini R: Relationship between follicle size and ultrasound-guided transvaginal oocyte recovery. Anim Reprod Sci 2001, 67:37-43.
87. Leibfried L, First NL: Characterization of bovine follicular oocytes and their ability to mature in vitro. J Anim Sci 1979, 48(Suppl 1):76-86

88. Cursino MS, Zanetti ES, Saraiva NZ, Duarte JMB: Dinâmica Nuclear De Oócitos De Veado-Catingueiro (Mazama Gouazoubira) Maturados In Vitro. In XVIII Congresso Brasileiro de Reprodução Animal: 3-5 junho 2009. MG, (Brasil): Anais do XVIII Congresso Brasileiro de Reprodução Animal, Belo Horizonte; 2009:12-14. http://www.cbra.org.br/pages/eventos/cbra18/ Posters.pdf. ISBN 1984-8471.

89. Graham LH, Reid K, Webster T, Richards M, Joseph S: Endocrine patterns associated with reproduction in the Nile hippopotamus (Hippopotamus amphibius) as assessed by fecal progestagen analysis. Gen Comp Endocrinol 2002, 128:74-81.

\section{doi:10.1186/1471-2148-14-40}

Cite this article as: Cursino et al:: The role of chromosome variation in the speciation of the red brocket deer complex: the study of reproductive isolation in females. BMC Evolutionary Biology 2014 14:40.

\section{Submit your next manuscript to BioMed Central and take full advantage of:}

- Convenient online submission

- Thorough peer review

- No space constraints or color figure charges

- Immediate publication on acceptance

- Inclusion in PubMed, CAS, Scopus and Google Scholar

- Research which is freely available for redistribution

Submit your manuscript at www.biomedcentral.com/submit
C) Biomed Central 